\title{
University industry links and product innovation: cooperate or contract?
}

\author{
Jaider Vega-Jurado ${ }^{1,4 *}$, Sean Kask ${ }^{2,4}$; Liney Manjarrés-Henriquez ${ }^{3}$
}

\begin{abstract}
The role of universities in product innovation has received considerable attention over the past decade. However, little is known about how the type of formal university-firm interaction predicts innovative performance and the degree of novelty of new products. This research differentiates two forms of firm high-relational interaction with universities: R\&D contracting and cooperation. We exploit the panel structure of a dataset of 5,858 Spanish manufacturing firms with fixed-effects models. The empirical analysis finds that, although both contracting and cooperation predict product innovative performance, the two activities differ in the degree of novelty of new product outcomes. The implications are that the codified nature and asymmetric scope of R\&D contracting is more suitable for exploitative innovation, resulting in product innovation that is incremental in nature. On the other hand, the possibility to exchange and create tacit knowledge and the explorative nature of R\&D cooperation provide firms with the opportunity to better access the broad knowledge base of universities, leading to product innovations with a higher degree of novelty.
\end{abstract}

Keywords: R\&D cooperation; R\&D contracting; innovation; universities; product novelty.

Submitted: January $26^{\text {th }} 2017$ / Approved: August $8^{\text {th }} 2017$

\section{Introduction}

The academic literature consistently emphasizes that firms rarely innovate alone and that the development of new products increasingly depends on the firm's capacity to access and exploit external sources of technological knowledge (Laursen and Salter, 2006). Thus innovation is recognized as a distributed and interactive process among a number of economic actors rather that the province of individual firms (West et al., 2014).

Among the wide variety of agents with which firms can relate, universities have taken pride of place as partners, and academic research has come to be considered as one of the engines of industrial innovation (Perkman et al., 2013). Based on this belief, many OECD governments have launched, starting from the late 1970s, important initiatives to encourage greater interaction between universities and firms. However, despite this interest, tracing the effects of universities on industrial innovation has been a difficult task because of the wide spectrum of mechanisms through which knowledge may be exchanged as well as the complex set of factors that moderate the relationships between these agents (Ahrweiler, Pyka and Gilbert, 2011). University-industry links may involve a number of different organizational arrangements, ranging from collaborative research to temporary personnel exchanges. In this sense, our knowledge on the role of universities in industrial innovation is still limited since much of the existing research focuses on low-relational activities, such as patenting and licensing, while largely neglecting the linkages that are more intensive and used by firms more often, such as joint research and contract research (D'Este and Patel, 2007). This is especially true when it comes to the characteristics of the firm strategy for exploiting university knowledge and the use of systematic, large-scale empirical data to analyze it. As a result, multiple and even contradictory messages emerge from the empirical works carried out so far. Thus, while some studies show that university-industry links positively affect firms' innovative performance (Aschhoff and Schmidt, 2008; Bellucci and Pennacchio, 2016), others reveal an insignificant or even negative relationship (Miotti and Sachwald, 2003; Tsai and Wang, 2009).

In this paper, we argue that in order to disentangle the role of universities in industrial innovation, it is important to pay more attention to the specific characteristics of the interaction channel. In particular, we focus on two alternative formal arrangements with universities: R\&D contracting and cooperation. According to Perkmann and Walsh (2007), these two types of links imply a higher level of relational involvement between universities and firms compared to other mechanisms such as mobility (e.g. academic entrepreneurship, human resource transfer) and transfer links (e.g. licensing of university-generated IP). Therefore, they may provide a better understanding of the interactive nature of innovation processes. As these authors point out, "in the context of open innovation, it is particularly the links with high relational involvement that are of interest, as they facilitate the building and maintenance of interorganizational relationships" (Perkmann and Walsh, 2007: 563).

The present study addresses the following questions: (1) Are (both types of) high-relational research interactions with universities (R\&D contracting and cooperation) significant predictors of firm innovative performance? (2) If so, how do R\&D contracting and cooperation with universities differ in terms of the novelty of product innovation and knowledge generated? In so doing this study makes several contributions to the literature.

First, while previous studies have focused on the impact of cooperation with universities on different measures of innovative performance, no detailed empirical evidence exists on the role of contract

(1) Universidad del Norte- Business School. Barranquilla-Colombia.

(2) SAP Consultant, Business Transformation Services. Switzerland

(3) Universidad Autónoma del Caribe, Facultad de Ingeniería. Barranquilla, Colombia.

(4) INGENIO (CSIC-UPV), Universitat Politècnica de València, Spain.

*Corresponding author: jaiderv@uninorte.edu.co

ISSN: 0718-2724. (http://jotmi.org)

Journal of Technology Management \& Innovation @ Universidad Alberto Hurtado, Facultad de Economía y Negocios.

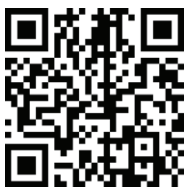


research; we have not found any study that simultaneously considers the effects of these two types of university-industry relationship on firm innovative performance. This is surprising given that the differences between collaboration, as a hybrid form of boundary-spanning organization, and external contracting to the market are stressed in the management literature (Lucena, 2011). This study builds on a clear distinction between cooperation and contracting and thus sheds light on the process through which universities may influence innovation.

Second, this work is not only among the first to compare the effect of university-industry links derived from two types of relationships, but it also carries out the analysis using panel data. Many of the empirical studies on university-industry relationships have drawn mainly from survey data, especially those coming from the Community Innovation Surveys (CIS). The use of this kind of data has allowed researchers to consider large samples of firms belonging to different industrial sectors, thus gaining a broad view of the phenomenon. However, most of these studies have a drawback in that they are cross-sectional and employ a controlling-on-observables estimation approach, which makes it difficult to account for certain sources of endogeneity (Lucena, 2011).

This article is organized in the following way. First, we discuss the potential effects of $\mathrm{R} \& \mathrm{D}$ contracting and cooperation with universities on firm innovative performance. We then move to a description of our research design followed by the presentation of the empirical results. We conclude by discussing the implications of our findings and possible future research lines.

\section{Literature Review}

\section{R\&D Contracting and University-Industry Cooperation as Innovation Strategies}

Schartinger et al. (2002 identify sixteen types of 'channels' or 'mechanisms' through which knowledge may be transferred between academics and industry personnel, grouped into four categories: joint research, contract research, mobility, and training. Using this classification as a starting point, Perkmann and Walsh (2007) suggest a more general typology by distinguishing university-industry relationships from other mechanisms such as human mobility or technology transfer. According to these authors, while the former imply links with a high-relational involvement where university researchers and industry employees work together on a specific project, the latter are more generic as they do not necessarily require face-to-face contact between academics and industry users.

The higher-involvement relationships are precisely the focus of this paper: R\&D contracting and R\&D cooperation. Although there is some debate in the literature on the existence of a sharp distinction between these two types of relationships, the organizational literature on the boundaries of the firm has stressed several differences between cooperation and contracting as innovation governance modes, which are equally applicable in the context of university-industry links. From a transaction cost perspective, contracting represents a governance mode close to market structure, in which the firm opts to farm out to universities, entirely or partially, the development of an R\&D project. In this kind of arrangement firms specify unilaterally what type of expertise they require (specific objectives and deliverables), and the academic researchers perform the assignment against payment (Perkmann and Walsh, 2007). In contrast, cooperation represents a hybrid governance mode between hierarchical transactions within firms and arms-length transactions in the market place. In collaborative arrangements both parties participate in the activities and contribute to the relationship by sharing knowledge and pooling resources.

Due to these differences in the organization of the relationship, contracting and cooperation vary not only in terms of the firm's control and ownership of outcomes, but also in their capacity to ease the exchange of knowledge and/or resources between academics and industry employees. Therefore, it is reasonable to assume that the effect of university-industry relationships on industrial innovation is likely to differ across the type of agreement adopted for organizing the relationship.

Related to $\mathrm{R} \& \mathrm{D}$ contracting, the literature has documented a number of expected benefits. In general, it has been suggested that this strategy allows a firm to tap into knowledge and resources from external partners as well as to focus more on its internal core capabilities, thereby facilitating faster product development (Tsai and Wang, 2009). In the specific case in which the provider of R\&D services is a university, the benefits of $R \& D$ outsourcing may be even higher since universities may provide different and complementary skills and resources with a large potential for learning (Un et al., 2010) .

Bearing in mind the above-mentioned aspects and the fact that in $\mathrm{R} \& \mathrm{D}$ contracting the activities are explicitly commissioned by the firm, it is reasonable to expect a positive effect of this strategy on a firm's innovative performance. However, R\&D outsourcing to universities may encounter some particular problems that may limit its success as innovation strategy. On the one hand, contracting may lead the firm to lose the capacity to develop the R\&D activities internally, thus weakening its technological competences. In addition, contracting may imply some extent of knowledge leakage from the firm, which in turn may compromise the distinctiveness of the innovative outcome. Further, problems of culture clashes and bureaucratic inflexibility may hinder the transfer of knowledge from universities to industrial firms (Knudsen, 2007). In these situations, more integrative strategies are required in order to facilitate the assimilation and exploitation of university knowledge. Cooperation, therefore, appears as an important technology acquisition alternative. By cooperating with universities, firms may not only share the risks and costs associated with basic research, but also build capabilities they would not get by simply contracting out the work to meet their needs. Because of the close interaction during a collaborative agreement, not only the knowledge itself, but also the competencies of the partners can be shared (Bodas-Freitas and Verspagen, 2017; Fey and Birkinshaw, 2005). In this way, cooperation may be a more appropriate strategy to exploit a pool of different but complementary knowledge. 
Nevertheless, despite the potential benefits of cooperation with universities, this strategy may also suffer some limitations. In collaborative arrangements the objectives and outcomes are jointly defined by the partners and, taking into account the generation of output of high academic relevance primarily motivates university involvement, cooperation might be targeted at more basic research and be long-term oriented. In fact, there is a general belief that research partnerships between universities and firms are usually aimed at the development of basic research with no clear commercial application (Un et al., 2010). Thus, cooperation with universities may not directly influence the success of a firm's innovation output; rather, it may just be oriented to foster learning processes and capacity-building.

The empirical evidence on the effect of these two types of university-industry relationships is also not conclusive. In the case of $R \& D$ outsourcing, while a number of studies point to its benefits on firms' innovative performance, systematic empirical studies on its effectiveness remain scarce (Stanko and Calantone, 2011). Three exceptions are the papers by Tsai and Wang (2009), Vega et al. (2009a), and Fey and Birkinshaw (2005), which explore the effect R\&D outsourcing on technological innovative performance. In these studies R\&D outsourcing is found to have no significant effect on technological innovation, although none of them distinguishes the outsourcing of R\&D services to universities from the R\&D outsourcing to other agents.

Regarding cooperation, the empirical literature is more extensive but has produced contradictory results. Based on data for a large sample of Dutch innovating firms, Belderbos et al. (2004) find that firms that cooperate with universities in their R\&D activities show higher sales growth due to new products than firms that do not cooperate. However, there are studies that also use data from innovation surveys and come up with different conclusions. Miotti and Sachwald (2003), for instance, find that cooperation with public institutions has no significant effect on the share of turnover from innovative products.

In sum, we can find different arguments to support opposite expectations about the success of R\&D contracting and cooperation with universities as innovation strategies. On the one hand, R\&D outsourcing has the potential to promote a faster innovation process, but due to the barriers arising from the cultural and organizational differences between firms and universities, several coordination and communication problems may emerge from this strategy thus limiting its impact on innovative performance. On the other hand, although cooperation may enable the firm to face coordination problems more effectively than technology acquisition via market procurement, the basic or fundamental nature of the research activities characterizing this kind of arrangement may make difficult to obtain tangible outcomes, especially in the short term.

\section{The Novelty of the Innovation Outcome}

So far we have discussed the effects of university-industry relationships taking into account the organizational form adopted for managing the relationship. However, the search for innovation can span not only organizational boundaries but also technological ones, lea- ding to another dimension in the analysis: the degree of novelty of the innovation outcome (Kobarg, et al., 2017; D'Este et al., 2016). Along these lines, the literature review suggests that the benefits of university-industry relationships could be investigated by considering the explorative nature of interaction and the degree of novelty of innovative result (Bellucci and Pennacchio, 2016). Following March's (1991) dichotomy of exploration and exploitation, several researchers have addressed the analysis of $\mathrm{R} \& \mathrm{D}$ alliances by distinguishing between exploitative and explorative collaborations (Faems et al., 2005; García-Granero, et al., 2014). While the former is oriented to enhancing existing competences, the latter is aimed at creating new ones. Thus, explorative collaborations are accepted to be especially successful in the creation of products with a high degree of novelty or in the development of new technology in the form of patents; exploitative collaborations are related more to the improvement of existing products. To a large degree, this idea also goes hand-in-hand with the distinction between complementary versus supplementary knowledge. While supplementary knowledge may fit better with the firm's current knowledge base and can be expected to improve existing organizational competences, complementary knowledge is more likely to provide new ideas that lead to the development of new projects and use of existing skills in different ways (Knudsen, 2007). Traditionally, universities have been considered a source of complementary knowledge for the firms and, therefore, collaboration with these agents is considered to be of a more explorative-oriented nature.

However, in the light of the discussion presented in the previous section, the question that emerges is how the organizational form adopted for managing university-industry relationships influences the explorative nature of this relationship. In this sense, the underlying premise in this work is that the type of relationship (contracting or cooperation) may have different effects on innovative performance according to the degree of novelty of the innovation outcome. Since the literature on these effects is scarce, the present study does not state specific hypotheses but comments on the results.

\section{Methodology}

\section{Exploiting Panel Data}

The empirical analysis uses six waves (2004-2009) of the Spanish Technological Innovation Panel (PITEC). Like other Community Innovation Surveys, the PITEC is based on the OECD's Oslo Manual. The unit of analysis is the single enterprise, whether an independent firm or part of a group. We restrict the analysis to the manufacturing industry.

We exploit the panel structure of the data to account for unobserved heterogeneity by means of conditional fixed effects (CFE) models. Fixed effects are factors that remain constant over time yet may influence innovation and be particular to each individual firm, such as proximity to a world-class university, organizational structure, reputation and brand, industry, etc. Accounting for fixed effects reduces omitted variable bias and, along with the inclusion of the dimension of time, provides researchers with a closer experimental approximation (Angrist and Pischke, 2009). 
The survey asks firms whether they have introduced a new product or process, invested in innovation, or had ongoing or abandoned innovation activities during the period covered by the survey. A positive answer to one of these questions classifies a firm as innovation oriented. We use this selection criterion to restrict our analysis to the subsample of innovation-oriented firms. This decision was driven partly by the questionnaire design: only innovation-oriented firms fully complete all sections of the questionnaire, including those questions related to cooperation with external agents. Roughly $86 \%$ of the firms are innovation oriented. After deleting observations with missing values, we are left with an unbalanced panel of 5858 manufacturing firms over six periods.

\section{Definition of the variables}

\section{Dependent variables}

This paper uses two dependent variables to estimate the effect of university interaction mechanisms on innovative performance. A pair of variables measure the share of sales from product innovations that are new to the firm (INNFIRM) or new to the market (INNMARKET). These variables provide information on the novelty of product innovation and also how much of the firm sales such innovations account for. There is a fair amount of ambiguity in the literature surrounding terminology and definitions of what constitutes 'incremental' and 'radical' innovation. However, INNFIRM and INNMARKET are understood in the literature to capture the degree of product innovation from less to more novel, respectively. We log transform the variables (after adding 1) to account for skew and satisfy distributional assumptions in the models.

\section{$R \& D$ contracting and cooperation variables}

Our explanatory variables cover specific university interaction mechanisms, in particular R\&D contracting and cooperation. Although the main objective is to analyse firm interaction with universities, we control for the effect of relationships with other commercial agents on innovative performance. To analyse the effect of cooperation we draw specifically on the responses to questions about cooperation with external agents for R\&D and innovation activities. We define a set of two dummy variables indicating each of cooperation with universities (COOP_UNI) and commercial agents (COOP_COMM). In order to evaluate the effect of $R \& D$ outsourcing we draw on the responses to a question that asks firms to indicate expenditure on R\&D services by different external agents. This information allowed the construction of two dummy variables specifying R\&D contracting to universities (RD_UNI) and commercial agents (RD_COMM).

\section{Control variables}

We control for changes in several firm-level variables, namely the firm size measured in the log of revenue (LSIZE) and a dummy indicating whether the firm has sales in international markets outside of the European Union (INTERNATIONAL). Note that the firm size and market, in general, are controlled for in the fixed effects; these variables control for changes in firm size, such as through a merger or layoff. We include a variable to measure the intensity of internal $\mathrm{R} \& \mathrm{D}$ activities. The variable LEMP_RD is the natural logarithm of the percentage of employees who dedicate at least some of their time to R\&D activities.

\section{Estimation Approach}

Because many innovation-active firms do not achieve sales from new products, these variables are censored at zero and non-negative. If the censoring is not accounted for, the estimates can be biased. Censoring of a continuous variable expressed as a proportion leads to a significant difficulty in accounting for firm-specific effects (Reitzig and Wagner, 2010). Although a Tobit model is the appropriate estimator in censored cross-sectional analyses, there is no sufficient CFE Tobit estimator (Greene, 2004). Therefore, we compare the results of several econometric approaches.

We first estimate INNFIRM and INNMARKET using CFE ordinary least-squares (OLS) regression. Angrist and Pischke (2009) argue in favour of OLS over non-linear models; OLS does not depend on distributional assumptions of a latent variable and estimates the average effect of each covariate considering that the outcomes are actually zero for many firms. They contend that, while non-linear models in many cases provide accurate predictions regarding coefficient direction and significance within the bounds of true censoring, OLS is standardized, more parsimonious, and can be interpreted directly as average marginal effects.

Next, we estimate the models for INNFIRM and INNMARKET using the semiparametric fixed-effects Tobit. The method artificially trims the data and eliminates the fixed effects through differencing, resulting in a consistent estimator (Cameron and Trivedi, 2010: 808). The distribution of the errors in this method remains unspecified, and no distributional assumption is imposed on the unobservables.

Finally, we estimate the continuous variables with the CFE Poisson. The properties of the CFE Poisson both condition out fixed effects and account for censoring at zero. Even though INNFIRM and INNMARKET are not count data, the CFE Poisson is still applicable to continuous variables in log-log models because it is equivalent to the Generalized Method of Moments (GMM) estimator (Windmeijer and Santos Silva, 1997).

\section{Results}

Table 1 presents the definitions, descriptive statistics of the variables - which are reported prior to log transformation - and the pairwise correlation matrix.

Keeping in mind that the PITEC draws from a subset of R\&D active firms in the national innovation survey, $12.7 \%$ of the innovation-oriented firms engaged in active cooperation with universities. Although not presented in Table 1, 5.5\% of firms both contracted R\&D to and cooperated with universities concurrently. Stated differently, $43 \%$ of firms that cooperated with universities also report contracting R\&D to universities. This indicates that firms do not approach these activities as substitutes for one another and may engage in both types of interaction for different purposes. 
Table 1. Descriptive statistics and definitions of variables. Mean reported prior to log transformation. Within standard deviation in brackets. Correlation Matrix

\begin{tabular}{|c|c|c|c|c|c|c|c|c|c|}
\hline Variable & $\begin{array}{l}\text { Mean } \\
\text { (within s.d.) }\end{array}$ & (1) & (2) & (3) & (4) & (5) & (6) & (7) & (8) \\
\hline (1) INNFIRM & $16.571 \%(20.366)$ & & & & & & & & \\
\hline (2) INNMARKET & $10.741 \%(16.278)$ & $0.066^{*}$ & & & & & & & \\
\hline (3) RD_UNI & $0.096(0.189)$ & $0.027^{\star}$ & $0.061^{\star}$ & & & & & & \\
\hline (4) COOP_UNI & $0.127(0.202)$ & $0.048^{*}$ & $0.101^{*}$ & $0.433^{*}$ & & & & & \\
\hline (5) RD_COMM & $0.210(0.276)$ & $0.061^{*}$ & $0.090^{*}$ & $0.208^{*}$ & $0.155^{\star}$ & & & & \\
\hline (6) COOP_COMM & $0.212(0.264)$ & $0.072^{*}$ & $0.103^{*}$ & $0.177^{*}$ & $0.404^{*}$ & $0.227^{\star}$ & & & \\
\hline (7) LEMP_RD & $10.435 \%(9.101)$ & $0.132^{*}$ & $0.213^{*}$ & $0.169^{*}$ & $0.166^{*}$ & $0.177^{\star}$ & $0.117^{\star}$ & & \\
\hline (8) LSIZE & $5.70 \times 10^{7}\left(8.73 \times 10^{7}\right)$ & 0.008 & -0.007 & $0.121^{*}$ & 0.151 & $0.124^{*}$ & $0.176^{*}$ & $-0.180^{*}$ & \\
\hline (9) INTERNATIONAL & $0.818(0.179)$ & $0.053^{*}$ & $0.058^{*}$ & $0.067^{*}$ & $0.078^{*}$ & $0.071^{\star}$ & $0.080^{*}$ & $0.067^{*}$ & $0.287^{*}$ \\
\hline
\end{tabular}

Table 2 presents the regression results evaluating the effect of university contracting and cooperation of R\&D activities on firm innovative performance and the novelty of new products. The explanatory variables of interest are the two formal mechanisms through which firms interact with universities. Models I, III, and V present the results of fixed- effects OLS, Tobit, and Poisson estimations of the sales from products new to the firm (INNFIRM), and models II, IV, and VI present results from products new to the market (INNMARKET). The results are similar across the three econometric approaches in terms of sign and significance, giving us confidence in the robustness of the findings.

Table 2. University Interaction and Degree of Product Innovation

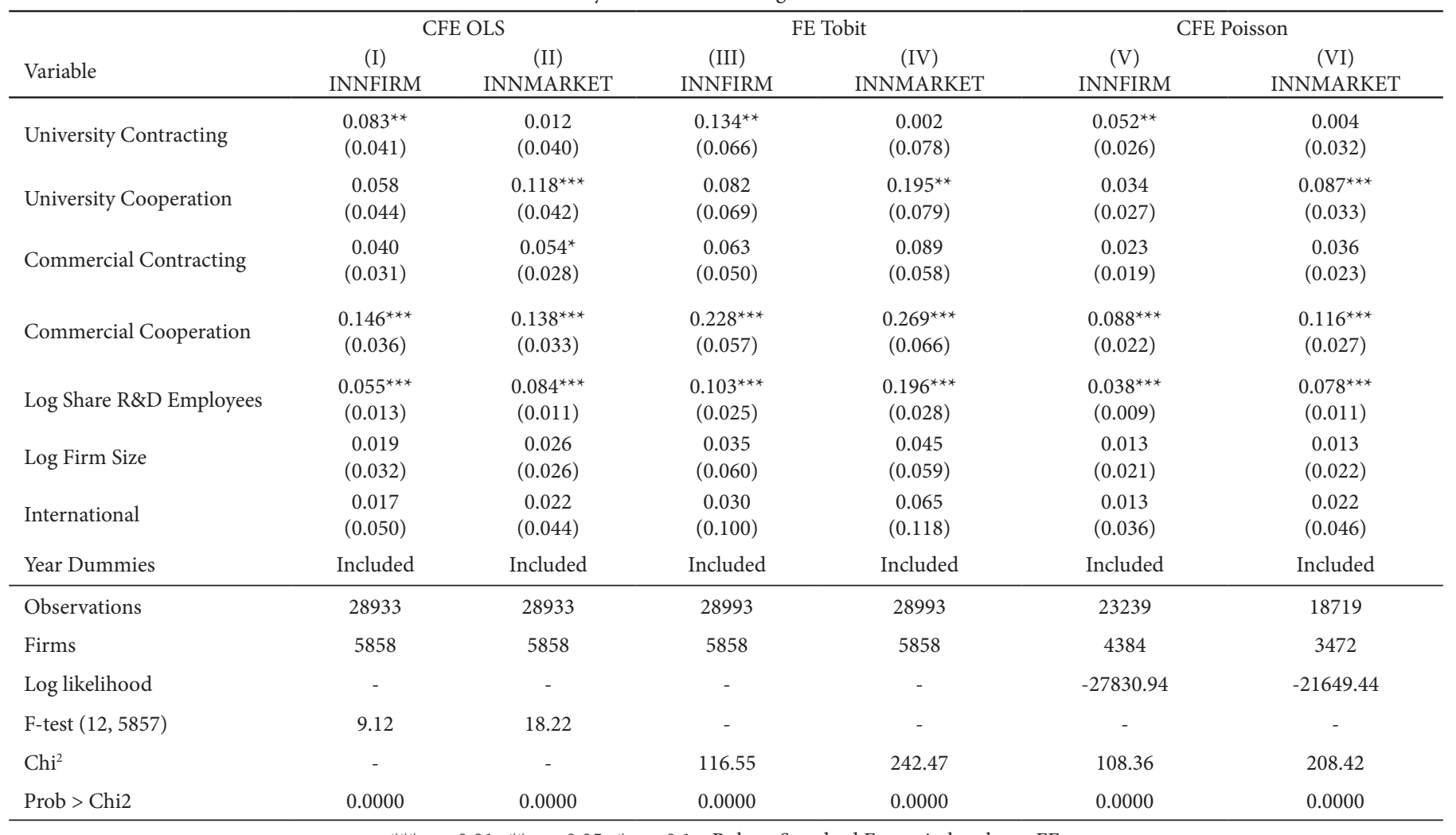

${ }^{* * *} \mathrm{p}<0.01{ }^{* *} \mathrm{p}<0.05{ }^{*} \mathrm{p}<0.1$ Robust Standard Errors in brackets. FE


Overall, interaction with universities has a positive and significant effect on the innovative performance of firms. However, the two interaction mechanisms have different effects according to the degree of novelty of product innovation. University contracting is significant only for innovations new to the firm, while the opposite relationship is seen with university cooperation, which is highly significant only for innovations new to the market.

Cooperating with commercial partners is a significant and positive predictor of both types of product innovation. Conversely, contracting to other firms does not predict product innovation (except in for the case of the OLS estimation in Model II, where it is significant only at the $10 \%$ level).

Unsurprisingly, internal R\&D intensity consistently and positively predicts innovation outcomes. In any case, it is informative to compare the magnitude of the coefficient across the degree of product novelty in Table 2. Returns to internal R\&D are higher for product innovations that are new to the market (Model VI) than for those that are merely new to the firm (Model V) as indicated by the larger coefficient.

\section{Discussion}

Recently, researches have emphasized the potential for universities as a source of external knowledge in firms' innovation processes (Rajalo and Vadi, 2017). The purpose of this study was to examine the effectiveness of university-industry links as an innovation strategy, paying special attention to those interactions that imply a higher level of relational involvement - namely R\&D contracting and cooperation - and taking into account the degree of novelty of the innovation outcome. Several important findings emerge from the analysis.

First, this research finds that high-relational interactions with universities positively predict firm innovative performance. In general, both $\mathrm{R} \& \mathrm{D}$ contracting and cooperation with universities appear as important strategies in order to introduce new products onto the market. This result is consistent with the open innovation literature and other types of network perspectives toward industrial innovation that highlight the prominent role of universities as innovation partners and their capacity to enhance firms' technological performance (Bellucci and Pennacchio, 2016).

Second, and even more important, this research uncovers a distinction between the degree of novelty of innovation outcome resulting from $R \& D$ contracting and that from cooperation with universities: contracting predicts product innovations that are new to the firm, but cooperation predicts market novelties. In general, the effect of cooperation with universities on more novel product innovations is consistent with some prior empirical studies (Bellucci and Pennacchio, 2016; Eom and Lee, 2010) and supports the view of university as an important source of complementary knowledge when exploring novel domains of technology. In contrast, the result from R\&D contracting partially differs from those in Vega-Jurado et al., (2009b) and Tsai and Wang (2009) on the effectiveness of R\&D outsourcing as innovation strategy. Although neither of these studies specifically analyses the contracting of $R \& D$ services to universities, all of them find that $R \& D$ outsourcing does not have a positive effect on innovative performance and in some cases even suggest a negative net effect. These results have been explained by firms' reluctance to share relevant knowledge because of the threat of unexpected transfer of knowledge to competitors. To be effective, contracting typically requires a bi-directional flow of knowledge insofar as the firm has to give the external provider access to its own knowledge base in order to achieve enhanced performance. In this sense, problems related to knowledge leakage and the opportunistic behaviour of the R\&D provider may arise during the task and may compromise the effectiveness of this strategy. In the light of our results, these problems seem to be less sensitive in the case of universities possibly because these agents are not potential competitors and the social norms in academia favor sharing knowledge rather than monopolizing it (Fey and Birkinshaw, 2005).

Another important implication arising from our results is that governance mode matters when considering relationships with universities. Thus different strategies to access university knowledge may lead to different innovative outcomes. So far, most empirical research about university-industry links has addressed these linkages in a very generic way while seldom linking the differences between the specific types of relationships with the nature of innovative outcome. Perhaps as a result, previous research has uncovered multiple and even contradictory findings regarding the role of universities in industrial innovation.

The interesting question at this point is why cooperation leads to more novel innovation outcomes than contracting. There are general differences between these strategies that may shed light on our findings. $\mathrm{R} \& \mathrm{D}$ contracting often takes the form of arms-length, iterative exchanges of explicit knowledge largely codified, for example, in the form of blueprints, contracts or technological packages (Lucena, 2011). Since both parties are responding to specific information, $R \& D$ contracting limits the scope to clearly defined problems and solutions. Furthermore, the firm often determines unilaterally the expertise required from the university, such that the relationship is asymmetric in nature (Perkmann and Walsh, 2007). In this way the R\&D contract initiated and defined by a firm is less explorative in nature and does not fully access the broad knowledge held in a university. Thus although universities are recognized as having a broad base of easily accessible knowledge, $\mathrm{R} \& \mathrm{D}$ contracting is limited in scope and possibilities for feedback such that firms are not able to take advantage of the full breadth of knowledge in a university to generate market novelties.

On the other hand, $\mathrm{R} \& \mathrm{D}$ cooperation, due to its interactive nature and sharing of resources, promotes the exchange and development of tacit knowledge and exposure to spillovers and heterogeneous knowledge. This may lead the collaboration down a different, explorative path than both parties were able to envision at the outset. Furthermore, cooperation increases the potential for mutual learning because the firm is concerned not only with the knowledge output per se but also with the process of developing that knowledge. Through 
cooperation with universities, firms may enhance their knowledge base and create new combinations making new technological breakthroughs more likely. The development of innovations with a high degree of novelty is full of uncertainty and often follows an unforeseeable development path. In this sense, cooperation can allow for ambiguity and adjustment during the development of an R\&D project.

On balance, the results of this study highlight that the ability of the firm to achieve a higher innovative performance from its relationships with external agents is a function of both the nature of external knowledge sources and the nature of the relationships forged with these sources. Exploring jointly the effect of these factors therefore appears as a prominent line of inquiry in order to go a step further in the analysis of effectiveness of external knowledge sourcing as innovation strategy.

\section{Limitations and Future Research}

Large datasets permit broader generalizability but necessarily omit many idiosyncrasies, such as how the observed relationship may differ according to industrial factors. Future research could seek to understand under what conditions our general results do or do not hold. Further, we have made a number of assumptions based on the literature regarding the nature of the differences in university $R \& D$ contracting and cooperation, such as communication patterns and the type of agreements. More detailed research could seek to break down and operationalize differences in contracting and cooperation with universities in order to see how these factors contribute to the innovative performance and novelty of product innovations.

Our research examined an important innovation outcome: sales from innovative products. There may be other tangible and intangible organizational consequences that differ between contracting and cooperation with universities, such as process innovation, appropriability of results, profitability and project costs, time to market, etc. Given that these two modes of formal interaction seem to have fundamental differences in terms of knowledge creation and transfer, future research could explore broader implications for firm performance.

\section{References}

Ahrweiler, P., Pyka, A. \& Gilbert, N. (2011). A New Model for University-Industry Links in Knowledge-Based Economies. Journal of Product Innovation Management 28 (2), 218-235.

Angrist, J.D., \& Pischke, J.-S.. (2009). Mostly Harmless Econometrics. Princeton, NJ: Princeton University Press.

Aschhoff, B., \& Schmidt, T. (2008). Empirical Evidence on the Success of R\&D Cooperation-Happy Together?. Review of Industrial Organization, 33 (1), 41-62.

Belderbos, R., Carree,M., \& Lokshin. B. (2004). Cooperative R\&D and firm performance. Research Policy, 33 (10), 1477-1492.
Bellucci, A., Pennacchio, L.(2016). University knowledge and firm innovation: evidence from European countries. Journal of Technology Transfer, 41 (4), 730-752.

Bodas Freitas, I.M., Verspagen, B. (2017). The motivations, institutions and organization of university-industry collaborations in the Netherlands. Journal of Evolutionary Economics, 27 (3), 379-412

Cameron, C.A., \& Trivedi, P.K. (2010). Microeconomics Using Stata. College Station, TX: Stata Press.

Cassiman, B., Di Guardo, M., \& Valentini, G. (2010). Organizing links with science: Cooperate or contract?: A project-level analysis. Research Policy, 39 (7), 882-892.

Chesbrough, H. (2003). Open Innovation: The New Imperative for Creating and Profiting from Technology. Harvard Business School Press.

D'Este, P., \& Patel, P. (2007). University-industry linkages in the UK: What are the factors underlying the variety of interactions with industry? Research Policy, 36 (9), 1295-1313.

D'Este, P., Amara, N., Olmos-Peñuela, J. (2016). Fostering novelty while reducing failure: Balancing the twin challenges of product innovation. Technological Forecasting and Social Change, 113, 280-292.

Eom, B.-Y., \& Lee, K. (2010). Determinants of industry-academy linkages and, their impact on firm performance: The case of Korea as a latecomer in knowledge industrialization. Research Policy, 39 (5), 625-639.

Faems, D., Van Looy, B., \& Debackere, K. (2005). Interorganizational Collaboration and Innovation: Toward a Portfolio Approach. Journal of Product Innovation Management, 22 (3), 238-250.

Fey, C.F., \& Birkinshaw, J. (2005). External sources of knowledge, governance mode and R\&D performance. Journal of Management, 31 (4), 597-613.

García-Granero, A.; Vega-Jurado, J \& Alegre, J (2014). Shaping the firm's external search strategy. Innovation Management, Policy \& Practice, 16 (3), 417-429.

Greene, W. (2004). Fixed Effects and Bias Due to the Incidental Parameters Problem in the Tobit Model. Econometric Reviews, 23 (2), 125-147.

Honoré, B.E., Kyriazidou, E., \& Powell, J. (2000). Estimation of tobittype models with individual specific effects. Econometric Reviews, 19 (3), 341 - 366.

Knudsen, M.P. (2007). The Relative Importance of Interfirm Relationships and Knowledge Transfer for New Product Development Success. Journal of Product Innovation Management, 24 (2), 117 138 
Kobarg, S., Stumpf-Wollersheim, J., Welpe, I.M. (2017). Universityindustry collaborations and product innovation performance: the moderating effects of absorptive capacity and innovation competencies. Journal of Technology Transfer (Article in press) pp. 1-29.

Laursen, K., \& Salter, A. (2006). Open for innovation: The role of openness in explaining innovation performance among UK manufacturing firms. Strategic Management Journal, 27 (2), 131-150.

Lucena, A. (2011). The Organizational Designs of R\&D Activities and their Performance Implications: Empirical Evidence for Spain. Industry \& Innovation, 18 (2), 151 - 176.

March, J.G. (1991). Exploration and Exploitation in Organizational Learning. Organization Science, 2 (1), 71-87.

Miotti, L., \& Sachwald, F. (2003). Co-operative R\&D: why and with whom?: An integrated framework of analysis. Research Policy, 32 (8), 1481-1499.

Perkmann, M., \& Walsh, K. (2007). University-industry relationships and open innovation: Towards a research agenda. International Journal of Management Reviews, 9 (4), 259-280.

Perkmann, M., Tartari, V., McKelvey, M., Autio, E., Broström, A., D’Este, P., Fini, R., Geuna, A., Grimaldi, R., Hughes, A., Krabel, S., Kitson, M., Llerena, P., Lissoni, F., Salter, A., Sobrero, M. (2013). Academic engagement and commercialisation: A review of the literature on university-industry relations. Research Policy, 42 (2), pp. 423-442.

Rajalo, S., Vadi, M. (2017). University-industry innovation collaboration: Reconceptualization. Technovation, 62-63, 42-54.

Reitzig, M., \& Wagner, S. (2010). The Hidden Costs of Outsourcing: Evidence from Patent Data. Strategic Management Journal, 31 (11), 1183-1201.
Schartinger, D., Rammer, C., Fischer, M., \& Fröhlich, J. (2002). Knowledge interactions between universities and industry in Austria: sectoral patterns and determinants. Research Policy, 31 (3), 303-328.

Stanko, M.A., \& Calantone, R. (2011). Controversy in innovation outsourcing research: review, synthesis and future directions. ReD Management, 41 (1), 8-20.

Tsai, M.-H., \& Wang, J. (2009). External technology sourcing and innovation performance in LMT sectors: An analysis based on the Taiwanese Technological Innovation Survey. Research Policy, 38 (3), 518-526.

Un, C.A., Cuervo-Cazurra, A \& Asakawa, K. (2010). R\&D Collaborations and Product innovation. Journal of Product Innovation Management, 27 (5), 673-689.

Vega-Jurado, J., Gutierrez-Gracia, A \& Fernandez-de-Lucio, I. (2009a). Does external knowledge sourcing matter for innovation? Evidence from the Spanish manufacturing industry. Industrial and Corporate Change, 18 (4), 637-670.

Vega-Jurado, J., Gutierrez-Gracia, A \& Fernández-de-Lucio, I. (2009b). La relación entre las estrategias de innovación: Coexistencia o Complementariedad. Journal of Technology Management \& Innovation, 4(3), 74-88.

West, J., Salter, A., Vanhaverbeke, W. \& Chesbrough, H. (2014). Open innovation: the next decade. Reseacrh Policy, 43, 805-811.

Windmeijer, F.A.G., \& Santos Silva, J.. (1997). Endogeneity in Count Data Models: An Application to Demand for Health Care. Journal of Applied Econometrics, 12 (3), 281-294. 